\title{
The response of a fractured crystalline reservoir to natural pressure buildup: Experiment results from the Bedretto Lab
}

\section{Other Conference Item}

Author(s):

Shakas, Alexis (D); Gholizadeh Doonechaly, Nima; Hertrich, Marian; Wenning, Quinn (D); Maurer, Hansruedi; Brixel, Bernard; Zappone, Alba Simona (D); Rinaldi, Antonio Pio (D); Obermann, Anne (D); Ma, Xiaodong (D); Kaestli, Philipp; Linwood, Paul; Hochreutener, Rebecca; Wiemer, Stefan (iD; Giardini, Domenico

Publication date:

2021-04

Permanent link:

https://doi.org/10.3929/ethz-b-000490190

Rights / license:

Creative Commons Attribution 4.0 International

Originally published in:

EGUsphere, https://doi.org/10.5194/egusphere-egu21-10324 
EGU21-10324, updated on 03 Sep 2021

https://doi.org/10.5194/egusphere-egu21-10324

EGU General Assembly 2021

(c) Author(s) 2021. This work is distributed under

the Creative Commons Attribution 4.0 License.

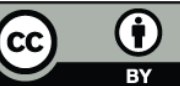

\title{
The response of a fractured crystalline reservoir to natural pressure buildup: Experiment results from the Bedretto Lab
}

\author{
Alexis Shakas, Nima Gholizadeh, Marian Hertrich, Quinn Wenning, Hansruedi Maurer, Bernard \\ Brixel, Alba Zappone, Antonio Rinaldi, Anne Obermann, Xiaodong Ma, Philipp Kaestli, Paul \\ Linwood, Rebecca Hochreutener, Stefan Wiemer, and Domenico Giardini \\ ETH Zurich, Department of Earth Sciences, Switzerland (alexis.shakas@erdw.ethz.ch)
}

The Bedretto Underground Laboratory for Geosciences and GeoEnergies, located in the Swiss Alps and situated under more than $1 \mathrm{~km}$ of granitic overburden, offers a unique field site to study processes in fractured rock. Currently, a total of six boreholes are available, four of them being permanently instrumented with monitoring equipment, and two dedicated as stimulation boreholes. One of the monitoring boreholes contains permanent packed-off intervals which record pressure changes and flow rate. The remaining three are instrumented with a variety of sensors, including fiber-optic micro-strain sensors, temperature monitoring, permanent geophones and accelerometers. All monitoring boreholes are either sealed with packers or cemented, and only the stimulation boreholes allow for outflow. During a period of several weeks, we were able to seal the two stimulation boreholes and allow the reservoir to approach ambient pressure conditions (more than $3 \mathrm{MPa}$ at the wellhead) while we monitored the response of the reservoir. The pressure buildup shows not only in the pressure data, but also as stress changes in the reservoir. During a depressurization phase, we quickly opened one borehole and subsequently performed time-lapse single-hole Ground Penetrating Radar (GPR) measurements. At a second depressurization phase, we continued the GPR measurements while opening the second borehole in a controlled manner. The changes in strain, pressure and GPR reflectivity illuminate the response of the reservoir when moving from ambient to atmospheric pressure at the wellhead, and reveal processes such as wellbore storage, pore-pressure variations and ultimately permeability changes in the reservoir. 